REVISTA CHILENA DE LITERATURA

Abril 2010, Número 76, 279 - 283

\title{
SOBRE BORGEANA, DE GRÍNOR ROJO ${ }^{1}$
}

\author{
Alicia Salomone \\ Universidad de Chile \\ aliciasalomone@yahoo.com
}

El ejercicio crítico y la autobiografía son escrituras menos distantes de lo que podría suponerse. Leer a otro supone leer con él, o contra él, pero siempre involucrando una subjetividad en la que se intersectan saberes disciplinarios e interdisciplinarios, inquietudes intelectuales y obsesiones propias (conscientes e inconscientes); todo lo cual se moviliza en relación con los elementos que provee ese otro (otro texto / otro cuerpo) que se ofrece a la lectura. Es precisamente desde este lugar de cruces que caracteriza al trabajo crítico, entendido como una praxis creativa que genera una escritura a partir de otra escritura, y que por lo tanto pone en juego un deseo: escribir para hablar de otro pero, inevitablemente, también para hablar sí mismo, desde donde quiero acercarme a Borgeana, el libro de Grínor Rojo que presentamos hoy.

En este recorrido, lo primero que llama mi atención son los ecos que, desde este texto, evocan preocupaciones que han perseguido a nuestro autor a lo largo de varios años, algunas de las cuales se han plasmado en los libros que él ha producido en la última década: el problema de las identidades, la cuestión nacional y sus derivas en tiempos de globalización, la relación cultural entre metrópolis y áreas periféricas, la problematización del canon literario considerando esa misma relación cultural asimétrica entre países, los nuevos enfoques teórico-críticos que, en las cuatro últimas décadas, están produciendo la renovación de los estudios literarios tras la crisis del estructuralismo y el marxismo dogmático ${ }^{2}$.

1 Este texto fue leído en la presentación de Borgeanas (Santiago: LOM, 2009), la que tuvo lugar el 10 de diciembre de 2009 en la Sala Domeyko de la Casa Central de la Universidad de Chile. Las remisiones al texto se indican mediante el número de página.

2 Me refiero, en particular, a Diez tesis sobre la crítica, Postcolonialidad y nación, Identidades nacionales y postnacionales. ¿De qué estamos hablando? y Las armas de las letras. Ensayos neoarielistas. 
Pero, junto con estos ecos, también percibo en el libro otras reverberaciones, que tienen más que ver con la presencia en el texto de la huella de una experiencia, la de un cierto placer de la lectura, al que Rojo se dispone cada vez que vuelve a Borges. Por mi parte, imagino ese placer como el efecto de un doble reencuentro. El primero me parece ligado a la dicha implícita en el adentrarse en la aventura, siempre azarosa y siempre apasionante, del desciframiento de un enigma textual. El segundo lo asocio con la seducción que parece ejercer en el crítico la indagación en otro misterio, no menos atrayente que el anterior, y que es el que le presenta el sujeto productor de la escritura. Un personaje que quiso dibujarse a sí mismo mediante una construcción tan artificiosa como la que ofrecen sus relatos (a estos fines, solo basta recordar el cuento "Borges y yo"), y al que Rojo perseguirá (detectivesca, borgeanamente) a través de los rastros que aquél va dejando en los pliegues de sus escondites retóricos, sean éstos los de la ficción narrativa o los (en buena medida, también ficcionales) de la autobiografía.

Antes de entrar a la propuesta de lectura que este libro nos ofrece, quisiera apuntar, sin embargo, algunas notas sobre el lugar que Rojo demarca para sí dentro del escenario crítico, ciertamente amplio, que se ha ido configurando en torno a la obra del escritor argentino. Fiel al estilo polémico que le es característico, y apelando a un lenguaje que, en busca de la complicidad del lector, reniega de los tecnicismos, aunque a veces deba recurrir a ellos, Rojo leerá a Borges a contrapelo, y no pocas veces en contra, tanto de las interpretaciones canonizadas como de las nuevas modas dominantes en el campo crítico. Si, por un lado, no le seduce especialmente ni el enfoque ni la jerga estructuralista desde la que muchos han trabajado, incluso concediéndole crédito a la rigurosidad de algunos análisis, como los de Jaime Alazraki y Guillermo Gotschlich (48-49), por otro lado, cuestiona abiertamente aquellas versiones que quieren hacer del cuentista un postmoderno avant-la lettre, que habría inaugurado en América Latina, en la primera mitad del siglo $\mathrm{XX}$, un fenómeno que ni siquiera se anunciaba todavía en los centros metropolitanos del poder cultural (Alfonso de Toro 14).

Demás está decir que no concuerda con la visión unilateral de Borges como un escritor oligarca y antipatriota, que levantó Roberto Fernández Retamar en su primer Caliban, el de 1971; una perspectiva de la cual el mismo crítico cubano se retractaría años más tarde. Finalmente, pero no por ello menos importante, a Rojo tampoco le convence el marginalismo contemporáneo que propone Beatriz Sarlo (10 y ss.), quien afirma que la originalidad de Borges radicaría en su capacidad para hacer una reapropiación irreverente de la tradición occidental, reformulándola, de manera "acriollada", desde los confines sur-atlánticos del mundo. Para nuestro autor, en cambio, lejos de representar la fuente de una originalidad verdadera o de un cierto reino de la libertad, la condición periférica de la escritura de Borges no haría sino poner de manifiesto el vacío, la escisión, que suele perseguir a los intelectuales del mundo (neo)colonizado, más visible aún cuando intentan encubrir ese vacío con máscaras creadas a la medida del colonizador (72). Una condición sobre la que reflexionaron in extenso intelectuales anticoloniales de la talla de Aimé Cesaire, Franz Fanon y Albert Memmi (72).

Instalando su tienda crítica a distancia de aquellas coordenadas, y en alianza con estas otras que le resultan más afines, Rojo leerá a Borges un poco a la manera como lo hizo con otra de las figuras canónica de nuestras letras, Gabriela Mistral, en Dirán que 
está en la gloria. Mistral, su libro de 1997. Es decir, apelando a un arsenal teórico-crítico diverso, donde resultan fundamentales las herramientas que le proveen el psicoanálisis, los estudios del discurso, la deconstrucción derrideana y también las teorizaciones feministas y postcoloniales ${ }^{3}$. Desde allí, lo que buscará es mostrar que la obra borgeana es resultado de la producción escritural de un sujeto complejo, que se resiste a definiciones "de una sola pieza"; insistiendo, por otra parte, -y éste es el pivote de su interpretación- en el carácter ineludiblemente contradictorio de su discurso. Desde allí, lo que Rojo pondrá en evidencia es la configuración de un sujeto escritural que emerge de una tensión productiva, generada a partir de ciertas determinaciones básicas. Determinaciones desde las cuales es posible identificar el origen de la visible ambivalencia identitaria que atraviesa toda la obra borgeana, y que tomará forma en el cuestionamiento constante de ciertos binarismos que son centrales en el andamiaje ideológico de Occidente (verdad/falsedad, realidad/ficción, originalidad/copia, civilización/barbarie, Uno/otro). Los que serán desafiados, una y otra vez, sin que ello suponga tampoco su superación o desarticulación definitiva.

Esa articulación fundamental, en opinión de Rojo, tiene que ver, por un lado, con una historia que configura a Borges como un sujeto colonizado, es decir, como miembro de una élite neonacional surgida en el siglo XIX latinoamericano, cuya formación cultural (de raigambre casi absolutamente centroeuropea) está impregnada de eso que Edward Said define, de modo ejemplar, en Orientalismo (1978) como el discurso colonial. Una discursividad desde la que se lleva a cabo la construcción ideológica del otro por parte de Occidente, y a partir de la cual los colonizados, tanto los de élite como los subalternos, cada uno con sus respectivas y obvias diferencias, se constituyen a sí mismos, simbólicamente, desde un vacío identitario que jamás logrará ser llenado. El que, sin embargo, suele ser sustituido por las sucesivas máscaras, más o menos adaptativas o reactivas, según sea el caso, que los colonizados adoptan para funcionar en el entramado subalternizante que predispone el discurso imperial.

Por otro lado, sin embargo, junto a esa condición que lo aprisiona, en el sujeto borgeano siempre persistirá un ansia, "nunca depuesta pero nunca alcanzada", de escapar a esos moldes impuestos por su casa (es decir, por su clase, nacionalidad, etnia y género), huyendo hacia lo indeterminado y abierto. Una libertad que, como dice Rojo citando líneas de Borges, le permitiría "galopar a campo traviesa, como lo hace Billy the Kid en 'El asesino desinteresado Bill Harrigan' o como lo hace Otálora en 'El muerto', porque 'nosotros (también el hombre que entreteje estos símbolos) ansiamos una llanura inagotable" (5). Un enunciado que, para nuestro autor, remite a un deseo que habría experimentado el niño-Borges, de contacto directo con la realidad, es decir, con el territorio más inmediato de la calle y del barrio, con el de esa ciudad que es Buenos Aires a comienzos del siglo XX, y finalmente con esos confines que se extienden hacia el norte y hacia el sur de la urbe; paisajes éstos últimos que quedarían magistralmente plasmados en los textos del Borges adulto, como "síntesis de una exterioridad menos concreta que soñada" (22), en palabras de Rojo.

3 Para un desarrollo más amplio de su perspectiva teórica, ver sus Diez tesis sobre la crítica. 
Pues, en efecto, ese deseo de libertad que persigue el niño-Borges jamás se concretará y, en cambio, se sustituirá (o sublimará) mediante el repliegue, primero, hacia el espacio protegido del jardín familiar, para recalar, finalmente, en esa retaguardia que constituye la biblioteca paterna. Un espacio donde encuentra esos "ilimitados libros ingleses" (23), que conformarán el universo simbólico en el que, desde la lectura (una lectura inevitablemente atravesada por su circunstancia histórico-contextual: la propia, la de su país y la de su época), buscará anclar la propia escritura. Será, entonces, de esas transacciones simbólicas entre los constreñimientos y los deseos, siempre truncos pero siempre renovados, desde donde se generará el núcleo de esa particular productividad escritural que Borges pondrá en marcha, como sostiene Rojo, mediante una superposición de sueños que confluyen en un jardín único: el jardín de la literatura, el universo representado en los libros, cuyo fin por excelencia es el de servir de antesala y postergación de la muerte (23).

Las coordenadas que, muy someramente, acabo de reseñar son las que guiarán la praxis crítica que Grínor Rojo despliega en su estudio, desde las cuales procederá a la resignificación de una serie de narraciones, entre ellas, Emma Zunz, El Sur, La intrusa, Deutsches Réquiem, El informe de Bodie, El otro, Ulrica y El Congreso. A través de estos cuentos, lo que podremos seguir es un trayecto diacrónico, que nos lleva desde los trabajos iniciales del cuentista, esos en los que Borges da rienda suelta a su entusiasmo nacionalista (v.g.: "El hombre de la esquina rosada"), en el contexto del retorno a un país donde ha hecho crisis el orden oligárquico, hasta los que el escritor produce en su vejez. Textos, estos últimos, en los cuales el desengaño frente a los sueños juveniles y el creciente conservadurismo de la perspectiva ideológica, el de "La intrusa" o "El informe de Brodie", por ejemplo, suelen ir de la mano de una actitud autorreflexiva y de la vuelta a un cierto tipo de realismo, que lleva al sujeto borgeano a mirarse y reevaluarse a sí mismo en el recorrido de un siglo, como ocurre en "El otro", de El libro de arena (1975), apelando para ello al pivote que le brinda el desmantelamiento de la oposición binaria viejo-joven.

Lo que queda en medio de estos extremos es lo que constituye el grueso de la obra de Borges, y por tanto, también, lo que concentra la mayor parte de los análisis textuales que se llevan a cabo en este libro. Un período que Rojo define como el del tránsito entre ese sujeto borgeano argentinista y latinoamericanista de las primeras décadas, que coquetea con cierta vanguardia, y ese otro en el que la distancia irónica y autoirónica se ha profundizado. Lo que, a su vez, es concomitante con el cambio operado en su literatura, que pasa del énfasis en el plano referencial hacia una perspectiva que prioriza el repliegue sobre el texto mismo, potenciando su propio mundo narrativo mediante estrategias radicalmente desconstructivas que se articularán con una práctica extensiva del trabajo intertextual.

Para explicar estos cambios, que son los que conducen a Borges a convertirse en el escritor de fama internacional que llega a ser, hay que tener en cuenta, en opinión de Rojo, el despliegue dos procesos. Por una parte, su creciente convencimiento de que la reivindicación de un pasado premoderno mediante una estética criollista era, ya en los años treinta del siglo XX, una batalla perdida, y que más valía dar respuesta a la creciente crisis cultural provocada por la eclosión de una sociedad y una cultura de masas mediante trayectos culturales y literarios alternativos. Por otra parte, ello tiene que ver también 
con la creciente dificultad de Borges para seguir afiliado con un nacionalismo político y estético que, por esas mismas épocas, estaba dando muestras (v.g., en Leopoldo Lugones) de una deriva fascistoide que aquél no quería acompañar. Así, concluye Rojo, Borges terminará entendiendo que ese fondo identitario que había perseguido en su juventud (en buena medida, por no haberlo experimentado cabalmente, a causa de su larga residencia en Europa), no era sino una máscara retórica, un simulacro como cualquier otro, que deberá abandonar para abrir paso a otra etapa de su escritura, la de los "juegos con el tiempo y con lo infinito", que serían la esencia de sus cuentos maduros (14).

Para concluir este comentario quisiera referirme solo a uno de los análisis que este libro nos ofrece, con el objeto de mostrar cómo se plasma esta propuesta crítica que parece abrirnos hacia direcciones tan disímiles que, en una primera mirada, podrían ser difíciles de compatibilizar. Me refiero al capítulo que Rojo dedica al cuento "Deutsches Réquiem", abordándolo desde la deconstrucción que allí opera entre la identidad del Uno y el otro. De este análisis, me interesó particularmente el develamiento de cómo el sujeto borgeano lidia con la oposición binaria entre nazismo y civilización occidental; un fantasma que también parece acosar a Borges, quien se había formado en y había admirado la cultura alemana desde sus días de juventud en Ginebra. Si uno de los ejes de la narración pasa por deslindar al nazismo de la cultura occidental, entendiendo al primero como la negación lógica del segundo; otra de las oposiciones a ser deconstruidas es la que enfrenta al carcelero Otto Dietrich zur Linde con el preso judío David Jerusalem, intentando hacer "del otro, el mismo". No obstante, como advierte Rojo, a diferencia de lo que ocurre en otros casos, en este texto la desconstrucción de las oposiciones binarias se detiene a medio camino, dando a entender que si bien Jerusalem constituye una parte de Otto zur Linde (por una línea genealógica que los une), ello no significa afirmar que él sea Otto zur Linde. Al respecto, sostiene Rojo, una cosa era decir que el criminal y el detective son equivalentes (por ejemplo, "La muerte y la brújula"), y otra cosa harto distinta era igualar, en el marco de los crímenes de guerra nazi, al victimario con su víctima judía (87). Sin embargo, ambos tienen en común una raíz, la cultura occidental, y no pueden dejar de ser fieles a ella sino al precio de la propia vida: "Yo agonicé con él, dice zur Linde, yo morí con él... por eso fui implacable". Desde allí, Rojo vuelve la mirada al escenario latinoamericano, para advertir cómo los criollos americanos, cuya autoconciencia, desde Sarmiento en adelante, era la de ser los portadores y promotores del proyecto occidentalizante, no pueden sino funcionar en el marco del discurso colonial como unos simples "otros"; por ende, como la negación del Uno, "el mismo", como a ellos, Borges incluso, les hubiera gustado creer. El ejemplo de "Deutsches Réquiem", en la lectura de Rojo, puede ser, entonces, un modelo para entender cómo la flexibilidad identitaria borgeana también encuentra sus límites cuando se enfrenta a ciertos valores a los cuales ese sujeto no está dispuesto a renunciar. Lo que, para nosotros, abre la posibilidad de reflexionar sobre el modo en que las estrategias borgeanas, aparentemente descontextualizadas, pueden y deben leerse a la luz y en diálogo con nuestra propia experiencia cultural. 
